\title{
Enhancing the ecological value of tropical agriculture through set-asides
}

\author{
Jake Bicknell ( $\square$ j.e.bicknell@kent.ac.uk) \\ University of Kent https://orcid.org/0000-0001-6831-627X \\ Jesse O'Hanley \\ University of Kent
}

\section{Paul Armsworth}

University of Tennessee, Knoxville

\section{Eleanor Slade}

Nanyang Technological University https://orcid.org/0000-0002-6108-1196

Nicolas Deere

University of Kent

\section{Simon Mitchell}

University of Kent

\section{David Hemprich-Bennett}

University of Oxford https://orcid.org/0000-0002-3555-4295

\section{Victoria Kemp}

Queen Mary University of London

\section{Stephen Rossiter}

Queen Mary University of London

\section{Owen Lewis}

University of Oxford

\section{David Coomes}

University of Cambridge

\section{Agnes Agama}

South East Asia Rainforest Research Partnership

\section{Glen Reynolds}

South East Asia Rainforest Research Partnership

\section{Matthew Struebig}

University of Kent https://orcid.org/0000-0003-2058-8502

\section{Zoe Davies}

University of Kent https://orcid.org/0000-0003-0767-1467 
Keywords: tropical agriculture, sustainability, biodiversity, agricultural expansion

Posted Date: March 19th, 2021

DOI: https://doi.org/10.21203/rs.3.rs-272185/v1

License: (c) (1) This work is licensed under a Creative Commons Attribution 4.0 International License. Read Full License 


\section{set-asides}

7 Authors: Jake E. Bicknell ${ }^{1 *}$, Jesse R. O’Hanley ${ }^{1,2}$, Paul R. Armsworth ${ }^{3}$, Eleanor M. Slade ${ }^{4,5}$,

8 Nicolas J. Deere ${ }^{1}$, Simon L. Mitchell ${ }^{1}$, David Hemprich-Bennett ${ }^{5,6}$, Victoria Kemp ${ }^{6}$, Stephen J. Rossiter ${ }^{6}$, Owen T. Lewis ${ }^{5}$, David A. Coomes ${ }^{7}$, Agnes L. Agama ${ }^{8}$, Glen Reynolds ${ }^{8}$, Matthew J. Struebig ${ }^{1}$, Zoe G. Davies ${ }^{1}$

Affiliations:

${ }^{1}$ Durrell Institute of Conservation and Ecology (DICE), School of Anthropology and Conservation, University of Kent, UK ${ }^{5}$ Department of Zoology, University of Oxford, UK 


\section{Abstract}

26

27 Agricultural expansion across the tropics is the primary driver of biodiversity declines and 28 ecosystem service degradation. However, efforts to mitigate these negative impacts may reduce

29 commodity production. We quantify trade-offs between oil palm cultivation and ecological 30 outcomes (biodiversity, above-ground carbon storage and dung nutrient cycling) across 31 different potential set-aside (uncultivated areas in agricultural landscapes) strategies. We show 32 that all set-aside configurations yield substantial gains in ecological outcomes. The best 33 strategy involves spatially targeted riparian reserves, such as those used in oil palm certification 34 schemes, where species occurrence can be doubled without reducing overall cultivation area.

35 Adopting this strategy throughout the 8 million hectares of plantations in Borneo would lead 36 to extensive improvements in ecological outcomes without losses to production area, and 37 consequently, enhancing agricultural sustainability. 
Agricultural expansion is considered critical to meeting the growing food demands of an increasing human population, yet it is also the primary driver of habitat loss across the planet $(1,2)$. With food demand predicted to double by 2050 (3), it is estimated that up to 1 billion hectares of previously uncultivated land will need to be bought under production to ensure food security $(4,5)$. Much of this land is expected to replace tropical forest $(6-8)$. Over the past three decades alone, more than 150 million hectares of tropical forest have been cleared for agriculture $(4,9,10)$. This leads to disproportionate biodiversity losses $(11-13)$, is a major driver of climate change (contributing $7-14 \%$ of global $\mathrm{CO}_{2}$ emissions (14-17)), and has negative impacts on multiple ecosystem functions and services, including soil fertility, soil stability and the provision of freshwater (18). Consequently, the challenge of reconciling rising food demand while safeguarding critical ecosystems is dependent on the manner in which tropical agricultural landscapes are established and managed.

Just four agricultural commodities (beef, palm oil, soy and wood products) drive $40 \%$ of tropical deforestation (19). Oil palm (Elaeis guineensis) occupies $~ 19.5$ million hectares in the tropics, mostly (82\%) in Southeast Asia (Supplementary Fig. 1). Since 1980, there has been a 15-fold increase in its production, and about half the people in the world currently rely on palm oil as part of their diet, as well as it being a key ingredient in animal feed, cosmetics and biofuels $(20,21)$. As such, it is predicted that oil palm agriculture will cover 29-33 million hectares by $2050(20,22)$. The associated deforestation is anticipated to negatively affect $54 \%$ and $64 \%$ of threatened mammals and birds globally (20), and release $\sim 330 \mathrm{Mt} \mathrm{CO}_{2}$ each year $(19,23)$, equivalent to almost half the average annual $\mathrm{CO}_{2}$ emissions from global aviation (24). 
63 Pressure is mounting on food supply chains to improve sustainability standards, or risk 64 continued strident calls for palm oil to be boycotted (25-27). However, switching to

65 alternatives will only exacerbate the problem $(20,25)$, given that producing palm oil requires

66 four to ten times less land per unit of oil than other vegetable oils $(20,28)$. To try to alleviate

67 environmental concerns, over 4000 companies have now adopted voluntary commitments to

68 source, produce and sell certified sustainable palm oil, which is cultivated conforming to social, environmental and agricultural best-practice guidelines $(23,29,30)$. Nonetheless, we have little understanding of how these guidelines may reduce the environmental impacts of agricultural expansion in tropical landscapes without compromising food security. Here, we quantify the trade-offs between oil palm cultivation and ecological outcomes (biodiversity, ecosystem function and service) across different potential set-aside strategies, which we identified through oil palm producer consultations (Fig. 1). We do this in the carbon- and biodiversity-rich forested landscapes of Borneo, which are considered the global epicenter of palm oil production $(31,32)$. Our results show that set-asides yield substantial ecological gains, and that locally optimized set-aside enhancements can augment carbon storage, soil nutrient cycling and biodiversity with little or no reduction in cultivated area.

\section{Set-aside in tropical agriculture}

82 The creation of set-asides, which are uncultivated areas within agricultural landscapes, have

83 long been used as a voluntary and regulatory practice to alleviate the adverse environmental effects of agriculture (33). Set-asides can offer important biodiversity refugia (34-36), help maintain ecosystem functions and services (37-39), and can support livelihoods (40). In relation to oil palm agriculture specifically, set-aside is often incorporated into national

87 legislation (Methods), as well as being required by voluntary sustainability certification 
systems (e.g. Roundtable on Sustainable Palm Oil (RSPO), which certifies 19\% of all palm oil). Nevertheless, set-aside policies vary greatly, and are not necessarily informed by scientific evidence (34).

Set-asides generally come in two forms in industrial-scale tropical agriculture: the maintenance of natural forest habitat on steep slopes $\left(25^{\circ}\right.$ and above; hereafter 'maximum slope for cultivation') to protect soils and watersheds, and, retention of forest near rivers ('riparian reserve width') to maintain hydrological systems (Supplementary Note 1). Each of these components can contribute to broader environmental outcomes beyond their intended objectives. For example, remnant forest on steep slopes or in riparian zones may provide habitat for biodiversity and maintain carbon stores (Supplementary Note 1) $(35,41-43)$. In industrial oil palm estates, most riparian reserve legislation stipulates fixed widths (e.g. $20 \mathrm{~m}$ or $50 \mathrm{~m}$ ) of forest are retained either side of the river, depending on the country/state. Conversely, some policies, including those of RSPO, vary based on river width and local context (e.g. $5 \mathrm{~m}$ of forest to be retained either side of small rivers, but up to $100 \mathrm{~m}$ of forest for larger rivers or areas considered to be particularly important for wildlife or habitat connectivity; Supplementary Note 1, Supplementary Table 1). Maximum slope for cultivation is often $25^{\circ}$, but this is climate and soil dependent (Supplementary Note 1).

\section{Impacts of set-aside policies on cultivation area}

Given the variability of set-aside policies, we examine the trade-offs between the amount of land available for cultivation and the ecological outcomes that can be realized for a suite of different set-aside configurations. We do so in a 119,000-hectare production landscape in Sabah, Malaysian Borneo, comprising four industrial-scale plantations and an array of remnant 
113 forest in set-asides (Methods; Supplementary Figs. 2-6, Supplementary Table 2). Before

114 evaluating the impacts of set-aside policies, we consulted major producers across the palm oil

115 industry to ensure our analyses focused on maximum slopes for cultivation and riparian reserve

116 widths that could be implemented feasibly in a real-world context (Methods). We then

117 examined different set-aside configurations, encompassing combinations of 20 riparian reserve

118 widths (in $5 \mathrm{~m}$ increments, ranging from 5 to $100 \mathrm{~m}$, on both sides of rivers) and 11 maximum

119 slope angles (ranging from 15 to $25^{\circ}$ ) per plantation, equating to 880 combinations across the

120 four plantations (220 in each). Larger riparian reserve widths and lower maximum slopes for

121 cultivation both mean that there is a greater area of set-aside in the landscape and,

122 correspondingly, less area available for cultivating crops.

123

124 Across all the set-aside configurations examined, 61-92\% of the landscape remained available

125 for cultivation. We find that riparian reserve set-aside comprised 0.5 to $10 \%$ of the landscape,

126 while set-aside based on maximum slope for cultivation accounted for 4 to $30 \%$. By

127 comparison, 20 and $50 \mathrm{~m}$ riparian reserve widths (corresponding, respectively, to current

128 policies for Sabah in Malaysia and Indonesia), combined with $25^{\circ}$ maximum slope, would

129 leave $89-91 \%$ of the landscape available for oil palm cultivation (Fig. 2A \& B).

130

\section{Optimizing trade-offs}

133 To assess the trade-off between the land available for cultivation, and ecological outcomes

134 (biodiversity, ecosystem function and ecosystem service), we combined our set-aside configurations with field-derived distributions for 235 species (150 birds, 19 non-volant

136 mammals, 21 bats and 45 dung beetles), dung nutrient cycling and LiDAR-derived above-

137 ground forest carbon storage (Methods). We express ecological outcomes of different 
landscape scenarios in terms of net and relative percentage changes in species occurrence, and total above-ground forest carbon storage and dung nutrient cycling under different set-aside

140 configurations. Net changes in species occurrence are calculated as the percentage change in

141 landscape area, whereas relative changes are calculated as a percentage change in species area.

142 For example, if a species occurred in $20 \%$ of the landscape in one set-aside configuration and

143 then $30 \%$ in another, this would equate to a $10 \%$ net increase and a $33 \%$ relative increase.

145 We evaluated two categories of set-aside policies. First, we considered 'uniform' policy 146 scenarios, meaning a one-size-fits-all approach, as implemented in most national/state-scale

147 legislation. Even with these very simple policies, the potential importance of set-asides in 148 delivering ecological gains in tropical agricultural landscapes becomes clear. In our landscape, 149 each $10 \%$ of the area in set-aside results in a net increase in species occurrence, ranging from $1503 \%$ to $23 \%$ across all 235 species (mean $=10 \%$ net increase, but up to $223 \%$ relative increase), 151 a $6 \%$ net increase in above-ground carbon storage, and $9 \%$ net increase in dung nutrient cycling 152 (Fig. 3 and Fig. 4A blue curve). We also evaluated 'variable' policies, under which we 153 optimized set-aside configurations, allowing these to vary between plantations in a way that maximized ecological outcomes at least cost to cultivation. To calculate the variable policy outcomes, we used multi-objective optimization models to maximize ecological outcomes

156 (species occurrence, above-ground carbon storage and dung nutrient cycling across set-aside 157 in the landscape) (objective one) and maximize area of the landscape available for oil palm 158 cultivation (objective two).

160 Compared to a uniform approach, the variable policy yields even higher levels of species 161 occurrence and above-ground carbon storage for any given percentage of the landscape 162 cultivated. Alternatively, the variable policy achieves specified levels of species occurrence 
163 and above-ground carbon storage at lower overall set-aside area than in the equivalent uniform

164 policy (Fig. 4). The greatest gains from the variable policy are obtained when set-aside

165 configurations result in $77-87 \%$ of the landscape cultivated (upper quartile of the difference

166 between uniform and variable policies; Fig. 4A,B). The most efficient of these is achieved

167 when $83 \%$ of the landscape is cultivated ('maximum efficient'). In this scenario, net species

168 occurrence within set-asides rises by $8.1 \%$ (range: $0.3-18 \%$ net increase in occurrence across

169 all species), from an average across species of $55 \%$ for the uniform policy to an average of

$17063 \%$ for the variable policy, and 3.8\% more above-ground carbon stored (Supplementary Table

1713 ; Fig. 4A,E). By comparison, achieving the same gain in ecological outcomes with the uniform

172 policy would require a reduction in cultivation area of 7.7\% (Supplementary Table 3; Fig.

173 4A,C). At maximum efficient cultivation levels, all species had increased occurrence under the 174 variable policy, compared to the uniform policy (Fig. 5 \& Supplementary Figs. 7-11;

175 Supplementary Note 2), with the greatest average gains among the birds, including endemic 176 and threatened species. We also find that at $90 \%$ ('business-as-usual'; broadly equivalent to 177 current policies in Indonesia and Malaysia) and 70\% ('high level set-aside') of the landscape 178 cultivated (Fig. 4C-F), the variable policy enhances ecological outcomes, albeit to a lesser 179 degree than when $83 \%$ of the landscape is planted (Fig. 4D,F; Supplementary Table 3; 180 Supplementary Note 2).

182 With $83 \%$ of the landscape cultivated, the corresponding set-aside (17\% of the landscape) can 183 be achieved through a range of uniform set-aside configurations of riparian reserve widths $184($ mean $=61 \mathrm{~m})$ and maximum slope for cultivation $\left(\right.$ mean $=22^{\circ}$; Supplementary Table 4$)$.

185 However, the flexibility of the variable policy, allows for more spatially targeted set-asides to 186 be distributed heterogeneously across the landscape to maximize ecological outcomes. As a 187 result, the variable policy could have lower overall set-aside with a mean riparian reserve width 
of $44 \mathrm{~m}$ and mean maximum slope for cultivation of $22^{\circ}$ to achieve the same ecological outcome (Supplementary Table 4). This is particularly pertinent for the variable set-aside configurations used in most certification schemes (Supplementary Note 1), because they should translate into improved ecological outcomes without the need to reduce cultivation area.

193 We also conducted our optimizations with a uniform maximum slope of $25^{\circ}$ but letting riparian reserve width vary. We did this because the palm oil industry told us that varying maximum slopes for cultivation would be less favorable from an operational perspective. Again, the variable policy resulted in ecological gains, albeit with reduced benefit compared to when the maximum slope for cultivation could also vary (Fig. 4A). Nonetheless, at current business-asusual cultivation ( $90 \%$ of the landscape), the reduction in gains compared to the fully variable policy were only marginal. Our findings additionally demonstrate that riparian reserves are the more important set-aside policy component for optimizing ecological outcomes. Indeed, when more than $\sim 85 \%$ of the landscape is cultivated, the impact of changes to maximum slope diminish, and riparian reserve width primarily drives changes in the amount of set-aside and, consequently, ecological outcomes (Fig. 2, Supplementary Fig. 12; Supplementary Note 3).

\section{The importance of plantation topography}

Across the tropics, agricultural plantations are less likely to occur on steep slopes, because they are more expensive to deforest and harder to cultivate successfully $(6,44)$. Landscape topography is, therefore, a key attribute affecting the impacts of set-aside policies. In our study

210 landscape, each plantation had a distinct topographic profile (Supplementary Table 2), varying 211 with the percentage of the plantation consisting of slopes above $15^{\circ}$, ranging from $18 \%$ of the

212 plantation (Plantation D) to 56\% (Plantation A; Supplementary Figs. 1 and 4). In general, 
213 rugged tropical landscapes with high proportions of steep areas, have more rivers and riparian

214 areas. Accordingly, the set-aside policy changes we explore have the most pronounced

215 consequences. This is highly relevant because much of the undeveloped land remaining in the

216 tropics comprises forest on steep slopes, as opposed to lowlands that have already been

217 converted to agriculture (6).

218

219 Implementing set-aside in tropical agricultural landscapes

220

221 On Borneo, an additional 30 million hectares (40\% of the island) is suitable for oil palm 222 cultivation and falls outside of protected areas (44). Of this, we estimated that 8 million hectares

223 (11\% of the island) could be potential set-aside in future plantations, as this is the area of forested slopes of $15-25^{\circ}$ and within $100 \mathrm{~m}$ of a river. Therefore, compared with existing plantations, for no net decrease in ecological outcomes, future plantations with optimized setasides (i.e. variable policies) could represent a potential increase in cultivated area of up to 7.7\%, yielding 189 million tonnes of crude palm oil over 20 years (Table 1).

228

Our findings are important for both conservation and food security debates as we show that set-asides can greatly enhance ecological outcomes without compromising the area of the landscape available for cultivation. This is critical because perceived losses to production may disincentivize growers from adopting best practice set-aside measures. To this end, our study shows that locally tailored riparian set-asides may be the best way to boost the biodiversity and ecosystem service value of tropical agricultural landscapes. 


\section{Methods}

\section{Study landscape}

240 Our study site is made up of four oil palm plantations and a logged forest reserve in Sabah,

241 Malaysian Borneo (Supplementary Fig. 2). One of the plantations lies within the Stability of 242 Altered Forest Ecosystems (SAFE) project (https://www.safeproject.net/; 46). The other three 243 are commercial plantations owned by two Malaysian palm oil producers. Together, the study 244 area covers 119,000 ha of forest and plantation. Most of the remnant forest has been logged 245 two to four times over 30 years and contains few mature trees (47), although some areas are 246 less disturbed and are now formally protected. The surrounding agricultural matrix comprises 247 oil palm trees, which were planted $12-15$ years prior to our data collection. Remnant logged 248 forest areas are present within the agricultural matrix, occurring on steep slopes and alongside 249 some rivers, with widths between 5 and $470 \mathrm{~m}$ either side of the river. Each plantation has a 250 distinct topographic profile varying in ruggedness from 18 to $56 \%$ of the landscape above 15 degrees slope. The area of a plantation within $100 \mathrm{~m}$ of a river varies from 12 to $23 \%$ (Supplementary Table 2).

Across the study area, we sampled multiple taxonomic groups, above-ground carbon storage and dung nutrient cycling. Methods, locations, and sample sizes varied, but all encompassed logged forest and riparian forest fragments and oil palm (details for each group or function are provided below). Species occurrence data from the logged forest reserve was used to improve our estimates of species distributions, but were not used in the trade-off analyses.

260 We obtained plantation boundaries for the experimental landscape directly from plantation owners. We mapped rivers across the landscape using a combination of geographic information system (GIS) data from the Sabah DID and the Shuttle Radar Topography Mission (STRM) 
(http://srtm.usgs.gov) digital elevation model (DEM) at a resolution of $30 \times 30 \mathrm{~m}$. The DID

264 data included the location of rivers, but did not include hydrological information such as flow,

265 which is used to estimate channel width. To estimate flow, we first used the r.watershed module

266 in GRASS GIS to create raster files for flow accumulation and drainage direction, which were

267 then inputted into the r.stream.extract module to create a raster and vector of channels using

268 the flow accumulation and direction layers. We subsequently added network information to the

269 raw vector channels using an $\mathrm{R}$ script to find links between channels

270 (https://www.safeproject.net/dokuwiki/safe_gis/stream_networks). The STRM generated data

271 matched very closely with the governmental DID data, so we used the STRM generated river

272 network in our analysis, which allowed us to exclude small streams estimated to be under $5 \mathrm{~m}$

273 in channel width, because in all guidelines and legislation these size rivers receive no or very

274 small riparian reserves. We ground-truthed 20 rivers to ensure that predictions of channel width

275 were broadly accurate. To estimate and map slope across the landscape, the SRTM data was

276 further processed using the gdaldem_slope function (https://gdal.org/programs/gdaldem.html)

277 for Python to generate a raster of slope angles measured in degrees.

278

279 Palm oil producer consultations

280 Before undertaking our landscape analyses, we consulted palm oil producers to inform the

281 range of set-asides policies to be tested, to ensure that the policies tested were feasible to

282 implement from an industry perspective. We conducted semi-structured interviews with nine

283 representatives from seven of the largest palm oil producers, with plantations located in nine

284 different countries across Southeast Asia and West Africa. Collectively, these companies

285 manage about $9 \%$ of the world's industrial palm oil plantations, an area of land covering 1.7

286 million ha. From these consultations, two key set-aside components emerged, riparian reserve

287 widths and maximum slope for cultivation. Eight of the nine respondents felt that increasing 
riparian reserve width was both feasible and important for enhancing ecological outcomes

289 (biodiversity, ecosystem functions and ecosystem services). Additionally, all respondents

290 indicated that they would support the establishment of wildlife corridors within plantations,

291 with riparian reserves being the main way to achieve this. Four out of the nine respondents

292 were supportive of policy changes to maximum slope for cultivation, but explained that they

293 rarely cultivate slopes steeper than $20^{\circ}$.

294

295

Set-aside configurations used in the analyses

296 Set-aside configurations of maximum slopes for cultivation and riparian reserve widths were

297 assessed in a GIS. We created 20 different riparian reserve width layers by adding buffers of

298 5-100 $\mathrm{m}$ (in $5 \mathrm{~m}$ increments) around the river network. We created polygons for 11 different thresholds for maximum planting slope ranging from 15 to $25^{\circ}$ (in $1^{\circ}$ increments). These two

300 sets of layers were subsequently merged to produce 220 combined riparian reserve width and

301 maximum slope for cultivation layers and then clipped to each plantations (but not the forest

302 reserve) to produce 880 plantation-specific set-aside layers. Across the four plantations, this resulted in $220^{4}$ or $2,342,560,000$ unique ways to configure the landscape. The landscape configurations were overlaid with species distributions, above-ground carbon storage and dung nutrient cycling layers. These allowed us to examine and optimize trade-offs between between the amount of land available for cultivation and the ecological outcomes.

308 Each five-meter increase in riparian reserve width results in an increase in set-aside of just 0.44

$309-0.52 \%$ of total production area, staying more-or-less constant across the 20 riparian reserve 310 widths we tested (Fig. 2A). On the other hand, decreasing the maximum slope for cultivation 311 reduces planted area to a much greater extent, with a one-degree change leading to a $0.9-4.1 \%$ 312 reduction in cultivated area (Fig. 2B). 


\section{Bird biodiversity field methods}

315 We sampled bird communities via point counts at 376 sample locations across the landscape

316 spaced a minimum of $200 \mathrm{~m}$ apart. Our point count locations covered all habitats types across

317 the landscape. During each point count, a single experienced observer (SLM) recorded all bird 318 species heard or seen within a $50 \mathrm{~m}$ radius of the point for $15 \mathrm{~min}$, including fly-overs. We 319 conducted point counts between 05:50 and 11:00 in clear weather and these were repeated on 320 three separate occasions at each site between 2014 and 2016. For further details see (48).

322 Non-Volant mammal biodiversity field methods

323 Camera-traps (HC500 Hyperfire, Reconyx, WI, USA) were deployed at 121 locations across 324 the landscape between May and September 2015. Locations were separated by a mean distance of $1.4 \mathrm{~km}$ and were stratified to capture the heterogeneity of the landscape. The camera-traps were positioned at a standardised height of $30 \mathrm{~cm}$ and were deployed for 42 consecutive nights per location, yielding a total survey effort of 4,669 camera nights. For further details see (49).

\section{Bat biodiversity field methods}

330 We sampled bat communities via harp trapping at 294 sample points across the landscape from 2015 to 2016 . Locations were stratified to capture the heterogeneity of the landscape and

332 tactically to maximize captures. At each site and each year, we performed ten nights of trapping 333 using six four-bank harp traps (60 harp trap nights per site total) from 20:30 to 08:30. For 334 further details see (50). 
337 We sampled dung beetle (Scarabidae sp.) communities via baited pitfall traps at 197 sample 338 points across the landscape from 2015 to 2016. Traps were plastic containers $14 \mathrm{~cm}$ deep and $33913 \mathrm{~cm}$ in diameter, part-filled with a mixture of water, salt, detergent, and chloral hydrate.

340 These were placed flush with the soil surface. A muslin bag of human dung (c.25 g) was suspended $5 \mathrm{~cm}$ above the trap. Each trap was protected from rain by a plastic plate held $20 \mathrm{~cm}$ above it. Traps were set in the morning and left for $48 \mathrm{~h}$ before collection. For further details see $(51)$.

\section{Biodiversity species distribution predictions}

346 We generated presence-pseudo absence species distribution models (SDMs) for 235 species

347 (150 birds, 21 bats, 19 non-volant mammals, and 45 dung beetles). For each species, we constructed an ensemble model of six algorithms: generalized linear models (GLMs), generalized boosted models (GBMs), random forests (RFs), support vector machines (SVMs), multivariate adaptive regression splines (MARSs), and artificial neural networks (ANNs), with five repetitions of each algorithm. Accuracy of each model was assessed using cross-validation with a 70-30 split of the occurrence data into training and evaluation sets, repeating the procedure to combine the ensemble using the highest AUC (area under curve). A presenceabsence prediction was then made using the sensitivity-specificity (SES) equality metric. We did not use bioclimatic variables as predictors because we were working at a fine-resolution landscape-scale and there was not enough variability. Instead, we used location and landcover predictors (elevation, slope, distance to river and soil type), which are static and do not change with the configuration of the experimental landscape. As such, our estimated species distributions represent the largest possible predicted distribution for each species across the

360 landscape. Relative variable importance was computed using Pearson's correlations between 
361 predictions of the full model and with each variable iteratively removed. All SDMs were constructed using the SSDM package for R (https://www.r-project.org/).

\section{Dung nutrient cycling predictions}

365 Dung removal is an important part of the soil nutrient cycling process and reduces greenhouse 366 gas emissions (52). We measured nutrient cycling via dung removal at 309 sample points across 367 the landscape. At each location, $700 \mathrm{~g}$ of dung were placed under a rain cover and, 24 hours 368 later, any remaining dung was collected and weighed. We also used three 369 evaporation/precipitation controls, comprising $700 \mathrm{~g}$ piles which were not accessible to fauna.

370 For further details see (51). To estimate dung removal across the entire landscape, we used 371 residual corrected ordinary regression kriging between our point estimates, and landscape level predictors implemented in SAGA GIS. We predicted dung removal using the same predictors as for the species distribution models, plus dung beetle diversity and non-volant mammal diversity (summed from our species distribution models), due to the relationship between mammals and dung beetles $(53,54)$.

377 Above-ground carbon storage predictions

378 To estimate above-ground carbon stored across the landscape we used data from the Carnegie 379 Airborne Observatory-3. The dataset combines airborne Light Detection and Ranging (LiDAR)

380 with satellite imaging and other geospatial data to map forest above-ground carbon density at $38130 \mathrm{~m}$ resolution throughout the Malaysian state of Sabah, Borneo. For further details see 382 (55,56). In our trade-off analyses that included above-ground carbon storage, we only considered pixels above a threshold of 35 tonnes of carbon per hectare, to ensure we were only considering High Carbon Stock forests. 
386 Estimating the trade-off between cultivation and ecological outcomes

387 To describe species occurrence, and total above-ground forest carbon storage and dung nutrient

388 cycling responses to changes in the proportion of the landscape cultivated, we fit a linear 389 regression model with quadratic and cubic terms (due to non-linear response of most species)

390 in the general form:

$$
y=b_{0}+b_{1} x+b_{2} x^{2}+b_{3} x^{3}
$$

392

393 where $y$ is the proportion of the landscape occupied by a given species or total above-ground

394 forest carbon storage and dung nutrient cycling, $x$ is the proportion of landscape cultivated,

395 and $b_{0}, \ldots, b_{3}$ are regression model coefficients.

396

397 For each species, above-ground carbon storage and dung nutrient cycling we then calculated

398 the slope $\left(1^{\text {st }}\right.$ derivative $)$ of the model, which characterizes the strength of the relationship

399 between the ecological outcome and the proportion of the landscape cultivated. As a proxy for

400 the linearity of each trade-off curve, we also calculated acceleration $\left(2^{\text {nd }}\right.$ derivative), which

401 measures how the rate of change for the trade-off curve is itself changes.

402

403 


\section{Optimization of trade-offs}

405 We formulated a mixed integer linear programing (MILP) model to optimize set-aside policies

406 for riparian reserve width and maximum slope for cultivation across the oil palm plantations.

407 The objective of the model is to maximize ecological outcomes in set-aside, subject to a limit 408 on the area of land taken out of cultivation and put into set-aside. The model was run for a

409 range of different set-asides to produce Pareto-optimal curves of ecological outcomes, where:

I Set of biodiversity and ecological service/functions, indexed by $i$

$J \quad$ Set of palm oil plantations, indexed by $j$

$K \quad$ Set of riparian reserve widths, indexed by $k$

$L \quad$ Set of maximum slopes for cultivation, indexed by $\ell$

$c_{j k \ell} \quad$ Set-aside area in plantation $j$ given selection of riparian reserve width $k$ and maximum slope for cultivation $\ell$

$b \quad$ Maximum feasible set-aside area across the landscape $\left(b=\sum_{j \in J} \max _{k \in K, \ell \in L} c_{j k \ell}\right)$

$\theta \quad$ Parameter for controlling total set-aside area limit (range 0-1)

$A_{i} \quad$ Areal range size of biodiversity or ecological service/function $i$ across the landscape

$a_{i j k \ell} \quad$ Area of biodiversity or ecological service/function $i$ in set-aside in plantation $j$ by riparian reserve width $k$ and maximum slope for cultivation $\ell$

$w_{i} \quad$ Weight assigned to biodiversity or ecological service/function $i$

$\phi_{i} \quad$ Fraction of biodiversity or ecological service/function $i$ 's range that must be in set-aside areas

410 
and the following decision variables:

415

$$
x_{j k \ell}=\left\{\begin{array}{l}
1 \text { if riparian reserve width } k \text { and maximum slope for cultivation } \ell \text { are selected } \\
\text { for plantation } j \\
0 \text { otherwise }
\end{array}\right.
$$

$416 y_{i}=$ fraction of biodiversity or ecological service/function $i$ 's range protected across the landscape

419 The MILP formulation of our variable policy is then:

$$
\max \sum_{i \in I} w_{i} y_{i}
$$

s.t.

$$
\begin{array}{ll}
\sum_{j \in J} \sum_{k \in K} \sum_{\ell \in L} c_{j k \ell} x_{j k \ell} \leq \theta b & \\
\sum_{k \in K} \sum_{\ell \in L} x_{j k \ell}=1 & \forall j \in J \\
y_{i} \leq \frac{1}{A_{i}} \sum_{j \in J} \sum_{k \in K} \sum_{\ell \in L} a_{i j k \ell} x_{j k \ell} & \forall i \in I \\
x_{j k \ell} \in\{0,1\} & \forall j \in J
\end{array}
$$

421 Model (S1)-(S4) is a modified version of what is known in the site selection literature as a 422 "maximum covering" problem (57). The objective (S1) maximizes the weighted proportional 423 ecological outcome within set-asides. Constraint (S2) sets an upper limit (aka budget) on total 424 set-aside area across the landscape. Parameter $\theta$ is a user-specified value that can be adjusted up/down to increase/decrease the set-aside area budget. Equalities (S3) require selection of

426 exactly one policy for riparian reserve width and maximum slope for cultivation for each 427 plantation $j$. Inequalities (S4), meanwhile, determine the fraction of each ecological outcome $i$ 
within set-aside areas. Given the structure of the optimization model, constraints (S4) could be written as equalities, since each variable $y_{i}$ will automatically equal the value on the righthand-side. Finally, constraints (S5) impose binary restrictions on the $x_{j k \ell}$ variables for selecting riparian reserve widths and maximum slopes for cultivation.

432

433 To impose a uniform policy for riparian reserve width and maximum slope for cultivation 434 across all plantations, we introduce variable $u_{k \ell}$ equal to one if riparian reserve width $k$ and maximum slope for cultivation $\ell$ is selected as a standard, zero otherwise, and the following 436 side constraints:

$$
\begin{aligned}
& \sum_{k \in K} \sum_{\ell \in L} u_{k \ell}=1 \\
& x_{j k \ell}=u_{k \ell}
\end{aligned}
$$$$
\forall j \in J, k \in K, \ell \in L
$$

438 Equality (S6) requires selection of a uniform policy for riparian reserve width and maximum slope for cultivation, while equalities (S7) stipulate that all plantations $j$ must adopt the same policy.

442 We implemented our landscape set-aside optimizations in the OPL modeling language using 443 CPLEX studio version 12.9 (58), which employs branch-and-cut methods to solve MILPs. The 444 largest problem instance we solved had 237 continuous variables, 880 binary variables, and 243 constraints. We performed secondary optimization runs assuming a uniform maximum 446 slope for cultivation of $25^{\circ}$. We also ran a set of optimizations of specific combinations of riparian reserve width and maximum slope for cultivation to test existing policies in Malaysia and Indonesia. We then plotted where these lie on top of the Pareto-optimal curves. 


\section{Estimating improvements to palm oil cultivation across Borneo}

451 To calculate the area of Borneo suitable for oil palm cultivation, we clipped the dataset of 452 global oil palm suitability created by (44) to Borneo and then extracted and summed the area 453 of 'Suitable', 'High', and 'Perfect' categories across the island. We then revised this figure by 454 removing existing protected areas (from https://protectedplanet.net/) and existing oil palm 455 plantations (from https://atlas.cifor.org/). We then intersected the remaining area with all areas 456 falling between $15-25^{\circ}$ slopes (at a $90 \mathrm{~m}$ resolution), by following the same procedure 457 described above for assessing slopes across the study landscape. We estimated the area of 458 Borneo within $100 \mathrm{~m}$ of a perennial river using river networks created by Milieux 459 Environnementaux, Transferts et Interactions dans les Hydrosystèmes et les Sols (METRIS; 460 https://www.metis.upmc.fr/en/node/375). To calculate the potential average additional oil palm 461 trees across Borneo from optimizing plantations (Table 1), we applied a value of 125 oil palm 462 trees per planted hectare, based on data from plantations $\mathrm{C}$ and $\mathrm{D}$. To calculate the potential 463 average additional crude palm oil (CPO) yield over 20 years, we applied an average yield value 464 of 4.1 metric tonnes of CPO per hectare, per year assuming an oil extraction rate of $25 \%$, and 465 average fresh fruit bunch yield of 16.4 tonnes per hectare per year (data from plantations $\mathrm{C}$ and

$466 \mathrm{D}$ and are close to the average for Malaysia which is 4.2 tonnes of CPO per hectare per year 467 (http://www.fao.org/faostat/ and 60). 


\section{References}

470

471

472

473

474

475

476

477

478

479

480

481

482

483

484

485

486

487

488

489

1. B. Phalan, et al. Crop expansion and conservation priorities in tropical countries. Plos One. 8, e51759 (2013).

2. J. Poore, T. Nemecek, Reducing food's environmental impacts through producers and consumers. Science. 360, 987-992 (2018).

3. M. Springmann, et al. Options for keeping the food system within environmental limits. Nature. 562, 519 (2018).

4. D. Tilman, C. Balzer, J. Hill, B. L. Befort, Global food demand and the sustainable intensification of agriculture. Proc. Natl. Acad. Sci. 108, 20260-20264 (2011).

5. T. D. Searchinger, S. Wirsenius, T. Beringer, P. Dumas, Assessing the efficiency of changes in land use for mitigating climate change. Nature. 564, 249 (2018).

6. D. P. Edwards, et al. Conservation of tropical forests in the Anthropocene. Curr. Biol. 29, R1008-R1020 (2019).

7. T. Newbold, et al. Global patterns of terrestrial assemblage turnover within and among land uses. Ecography. 39, 1151-1163 (2016).

8. T. Newbold et al. Global effects of land use on local terrestrial biodiversity. Nature. 520, 45-50 (2015).

9. H. K. Gibbs, et al. Tropical forests were the primary sources of new agricultural land in the 1980s and 1990s. Proc. Natl. Acad. Sci. 107, 16732-16737 (2010).

10. M. C. Hansen, et al. Townshend, High-resolution global maps of 21st-century forest cover change. Science. 342, 850-853 (2013). 
490 11. T. Newbold, et al. A global model of the response of tropical and sub-tropical forest 491 biodiversity to anthropogenic pressures. Proc. R. Soc. B Biol. Sci. 281, 20141371 (2014).

492 12. Y. Clough, et al. Combining high biodiversity with high yields in tropical agroforests. $493 \quad$ Proc. Natl. Acad. Sci. 108, 8311-8316 (2011).

494 495

13. X. Giam, Global biodiversity loss from tropical deforestation. Proc. Natl. Acad. Sci. 114, 5775-5777 (2017).

14. G. R. van der Werf, et al. CO2 emissions from forest loss. Nat. Geosci. 2, 737-738 (2009).

15. C. A. Harvey, et al. Climate-smart landscapes: opportunities and challenges for integrating adaptation and mitigation in tropical agriculture. Conserv. Lett. 7, 77-90 (2014).

16. N. L. Harris, et al. Baseline map of carbon emissions from deforestation in tropical regions. Science. 336, 1573-1576 (2012).

17. X.-P. Song, et al. Global land change from 1982 to 2016. Nature. 560, 639 (2018).

18. J. C. Quezada, A. Etter, J. Ghazoul, A. Buttler, T. Guillaume, Carbon neutral expansion of oil palm plantations in the Neotropics. Sci. Adv. 5, eaaw4418 (2019).

19. S. Henders, U. M. Persson, T. Kastner, Trading forests: land-use change and carbon emissions embodied in production and exports of forest-risk commodities. Environ. Res. Lett. 10, 125012 (2015).

20. E. Meijaard, et al. Oil palm and biodiversity: A situation analysis by the IUCN Oil Palm Task Force (2018). 
511 21. E. Meijaard, D. Sheil, The moral minefield of ethical oil palm and sustainable

512 development. Front. For. Glob. Change. 2, 22 (2019).

513 22. FAO, "The future of food and agriculture - Alternative pathways to 2050. Rome." $514 \quad$ (2018).

515 23. S. Donofrio, P. Rothrock, J. Leonard, "Supply Change: Tracking Corporate 516 Commitments to Deforestation-Free Supply Chains (Forest Trends, Washington, DC).” $517 \quad(2017)$

518 24. E. Terrenoire, D. A. Hauglustaine, T. Gasser, O. Penanhoat, The contribution of carbon 519 dioxide emissions from the aviation sector to future climate change. Environ. Res. Lett. $520 \quad \mathbf{1 4}, 084019(2019)$.

25. S. Parsons, S. Raikova, C. J. Chuck, The viability and desirability of replacing palm oil. Nat. Sustain. 3, 412-418 (2020).

26. F. Taheripour, T. W. Hertel, N. Ramankutty, Market-mediated responses confound policies to limit deforestation from oil palm expansion in Malaysia and Indonesia. Proc. Natl. Acad. Sci., 201903476 (2019).

27. W. F. Laurance, et al. Improving the performance of the roundtable on sustainable palm oil for nature conservation. Conserv. Biol. (2010).

28. E. Meijaard, J. F. Abrams, D. Juffe-Bignoli, M. Voigt, D. Sheil, Coconut oil, conservation and the conscientious consumer. Curr. Biol. 30, R757-R758 (2020).

29. RSPO, “https://rspo.org/about. Accessed July 2020” (2020). 
30. R. D. Garrett, K. M. Carlson, X. Rueda, P. Noojipady, Assessing the potential additionality of certification by the round table on responsible soybeans and the roundtable on sustainable palm oil. Environ. Res. Lett. 11, 045003 (2016).

31. R. A. Mittermeier, N. Myers, C. G. Mittermeier, G. Robles, Hotspots: Earth's biologically richest and most endangered terrestrial ecoregions (CEMEX, SA, Agrupación Sierra Madre, SC, 1999).

32. D. L. Gaveau, et al. Rapid conversions and avoided deforestation: examining four decades of industrial plantation expansion in Borneo. Sci. Rep. 6, 32017 (2016).

33. J. V. Buskirk, Y. Willi, Enhancement of farmland biodiversity within set-aside land. Conserv. Biol. 18, 987-994 (2004).

34. S. H. Luke, et al. Riparian buffers in tropical agriculture: Scientific support, effectiveness and directions for policy. J. Appl. Ecol. 56, 85-92 (2019).

35. S. L. Mitchell, et al. Riparian reserves help protect forest bird communities in oil palm dominated landscapes. J. Appl. Ecol. 55, 2744-2755 (2018).

36. S. A. Scriven, et al. Testing the benefits of conservation set-asides for improved habitat connectivity in tropical agricultural landscapes. J. Appl. Ecol. (2019).

37. C. R. Woodham, et al. Effects of replanting and retention of mature oil palm riparian buffers on ecosystem functioning in oil palm plantations. Front. For. Glob. Change. 2, 29 (2019).

38. K. M. Carlson, et al. Raymond, Influence of watershed-climate interactions on stream temperature, sediment yield, and metabolism along a land use intensity gradient in Indonesian Borneo. J. Geophys. Res. Biogeosciences. 119, 1110-1128 (2014). 
39. K. M. Carlson, et al. Effect of oil palm sustainability certification on deforestation and fire in Indonesia. Proc. Natl. Acad. Sci. 115, 121-126 (2018).

40. S. Wunder, A. Angelsen, B. Belcher, "Forests, livelihoods, and conservation: broadening the empirical base" (0305-750X, Elsevier, 2014).

41. RSPO, "Principles and Criteria for the Production of Sustainable Palm Oil 2018" (2018).

42. "High Conservation Value Resource Network (2017) HCV Resource Network. Available at www.hcvnetwork.org. Accessed July, 2020.”

43. L. E. Pardo, et al. Land management strategies can increase oil palm plantation use by some terrestrial mammals in Colombia. Sci. Rep. 9, 7812 (2019).

44. J. Pirker, A. Mosnier, F. Kraxner, P. Havlík, M. Obersteiner, What are the limits to oil palm expansion? Glob. Environ. Change. 40, 73-81 (9).

45. A.M. Afandi et al., Managing Soil Deterioration and Erosion under oil palm. Oil Palm Bulletin 75, 1-10 (2017).

46. R. M. Ewers et al., A large-scale forest fragmentation experiment: the Stability of Altered Forest Ecosystems Project. Phil. Trans. Royal Soc. of London B: Biol. Sciences 366, 3292 (2011).

47. M. J. Struebig et al., Quantifying the biodiversity value of repeatedly logged rainforests: Gradient and comparative approaches from Borneo. Adv. in Ecol. Res. 48, 183-224 (2013).

48. S. L. Mitchell et al., Riparian reserves help protect forest bird communities in oil palm dominated landscapes. J. Appl. Ecol. 55, 2744 (2018).

49. N. J. Deere et al., High Carbon Stock forests provide co-benefits for tropical biodiversity. J. Appl. Ecol. 55, 997 (2018). 
50. D. R. Hemprich-Bennett et al., Altered structure and stability of bat-prey interaction networks in logged tropical forests revealed by metabarcoding. BioRivX doi: https://doi.org/10.1101/2020.03.20.000331

51. E. M. Slade et al., Biodiversity and ecosystem function of tropical forest dung beetles under contrasting logging regimes. Biol. Cons. 144, 166 (2011).

52. I. Piccini et al., Greenhouse gas emissions from dung pats vary with dung beetle species and with assemblage composition. PloS one 12, e0178077 (2017).

53. E. H. Raine, E. M. Slade, Dung beetle--mammal associations: methods, research trends and future directions. Proc. Royal Society B 286, 20182002 (2019).

54. E. Nichols et al., Co-declining mammals and dung beetles: an impending ecological cascade. Oikos 118, 481-487 (2009).

55. G. P. Asner et al., Mapped aboveground carbon stocks to advance forest conservation and recovery in Malaysian Borneo. Biol. Conserv. 217, 289-310 (2018)

56. T. Jucker et al., Estimating aboveground carbon density and its uncertainty in Borneo's structurally complex tropical forests using airborne laser scanning. Biogeosciences $\mathbf{1 5}$, 3811-3830 (2018).

57. C.S. ReVelle et al., Counterpart models in facility location science and reserve selection science. Env, Mod, Assess 7, 71-80 (2002).

58. IBM (2019) IBM ILOG CPLEX Optimization Studio V12.9.0 documentation. Available at: https://www.ibm.com/support/knowledgecenter/en/SSSA5P_12.9.0/ilog.odms.studio.hel p/Optimization_Studio/topics/COS_home.html

60. L. S. Woittiez, M. T. van Wijk, M. Slingerland, M. van Noordwijk, K. E. Giller, Yield gaps in oil palm: A quantitative review of contributing factors. European Journal of Agronomy. 83, 57-77 (2017). 
61. J.M. Lucey et al., Simplifed Guide: Management and Rehabilitation of Riparian Reserves.

\section{Acknowledgments}

606 We are grateful to numerous field assistants for help with fieldwork, and SAFE Project for 607 extensive support. We thank the Carnegie Airborne Observatory and Sabah Forestry 608 Department for use of the above-ground carbon LiDAR data. We also thank R. Nathan, M. Y. 609 Abdullah, V. Moduying and D. Aloysius, M. Ationg, J. Lucey, and S. Lord for their 610 involvement in the oil palm producer consultations, and D. Orme who developed the code used 611 to extract slope values from SRTM data. The research was supported by UK Natural

612 Environment Research Council (NERC) grant NE/K016407/1, as part of the LOMBOK 613 consortium of the Human Modified Tropical Forests (HMTF) programme.

614

\section{Author contributions}

616 JEB led manuscript writing, conducted the landscape and Borneo wide set-aside analyses, 617 species, above-ground carbon storage and dung nutrient cycling modelling, created the figures 618 and undertook the oil palm producer consultations. ZGD and MJS conceived the study concept 619 and analytical framework, contributed to the research design and co-wrote the manuscript. 620 JRO'H, with JEB, developed and ran the optimization framework. PRA advised on the study 621 concept and optimization methodology. EMS, NJD, SLM, DHB and VK provided biodiversity 622 data, and EMS additionally provided nutrient cycling data. ALA, ZGD, EMS and GR helped 623 with the design and delivery of the oil palm producer consultations. DAC contributed towards 624 the estimates of above-ground carbon. SJR and OTL contributed to research design and helped 625 secure funding. All authors provided editorial input on the manuscript. 
627 Competing interests

628 Authors declare no competing interests.

629

630 Data availability

631 DOIs for the ecological data are listed in Supplementary Table 5.

632

633 List of Supplementary Information:

634 Supplementary Notes 1-3

635 Supplementary Tables 1 to 5

636 Supplementary Figs. 1 to 12

637 
$638 \quad$ Figures

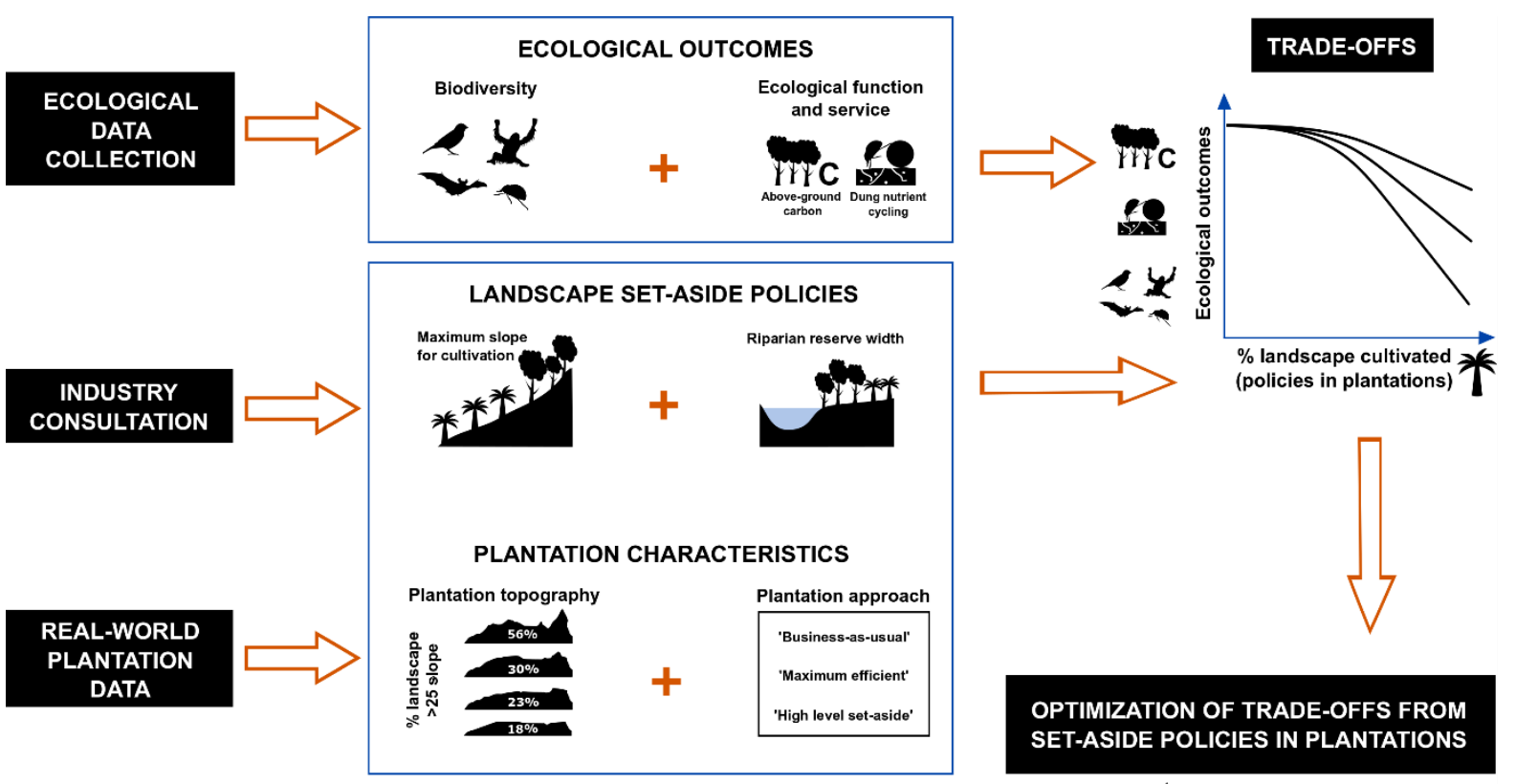

639

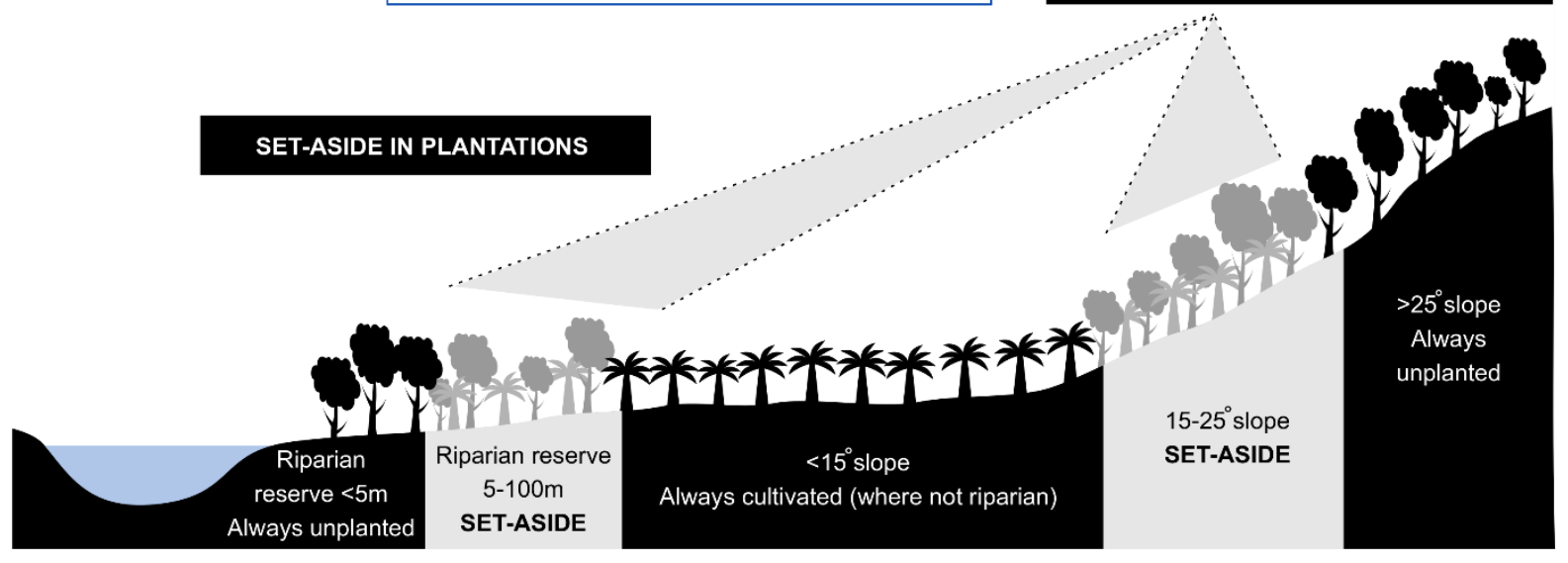

640 Fig. 1. Study workflow 
641
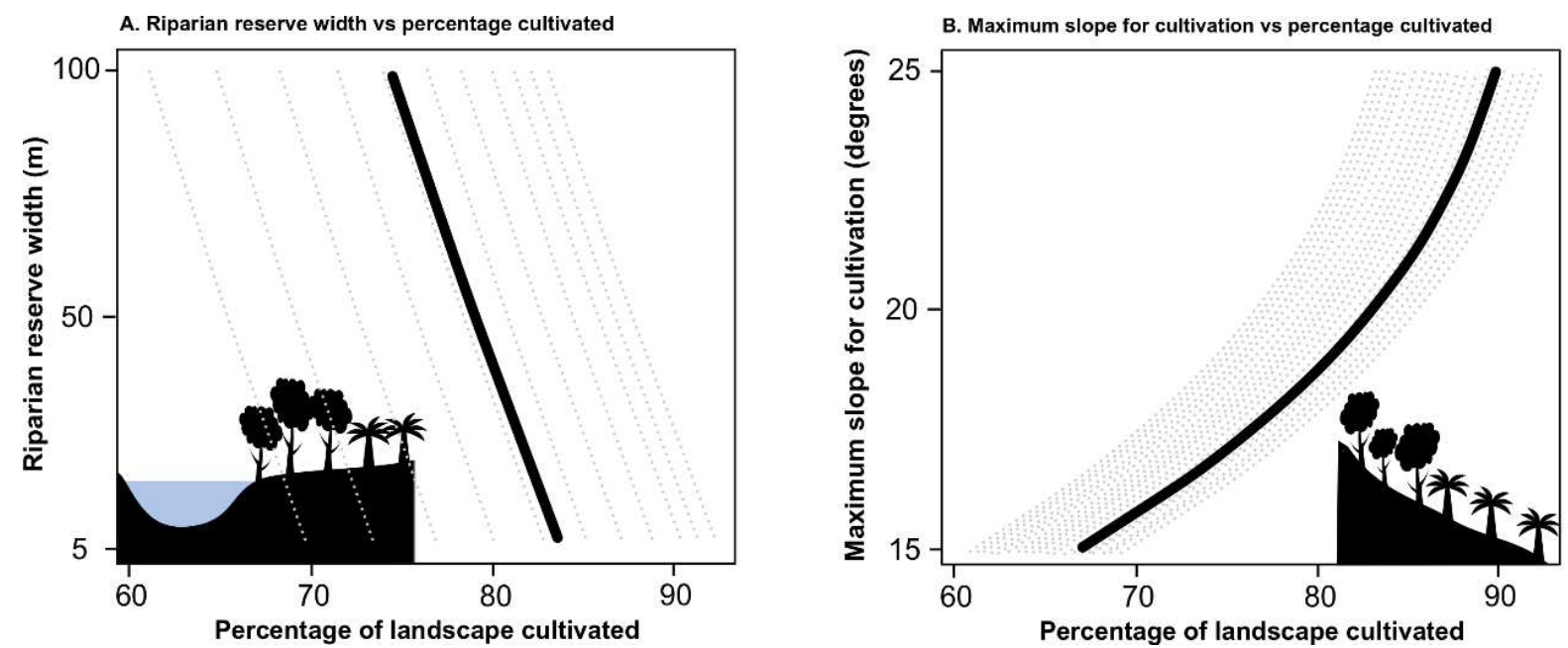

642

Fig. 2. Impacts of set-aside configurations on percentage of landscape cultivated

644 (A) Relationship between riparian reserve width and the percentage of the landscape cultivated.

645 (B) Relationship between maximum slope for cultivation and percentage of the landscape

646 cultivated. Dashed lines show all potential landscape set-aside configurations, and bold lines

647 show the mean. 
648

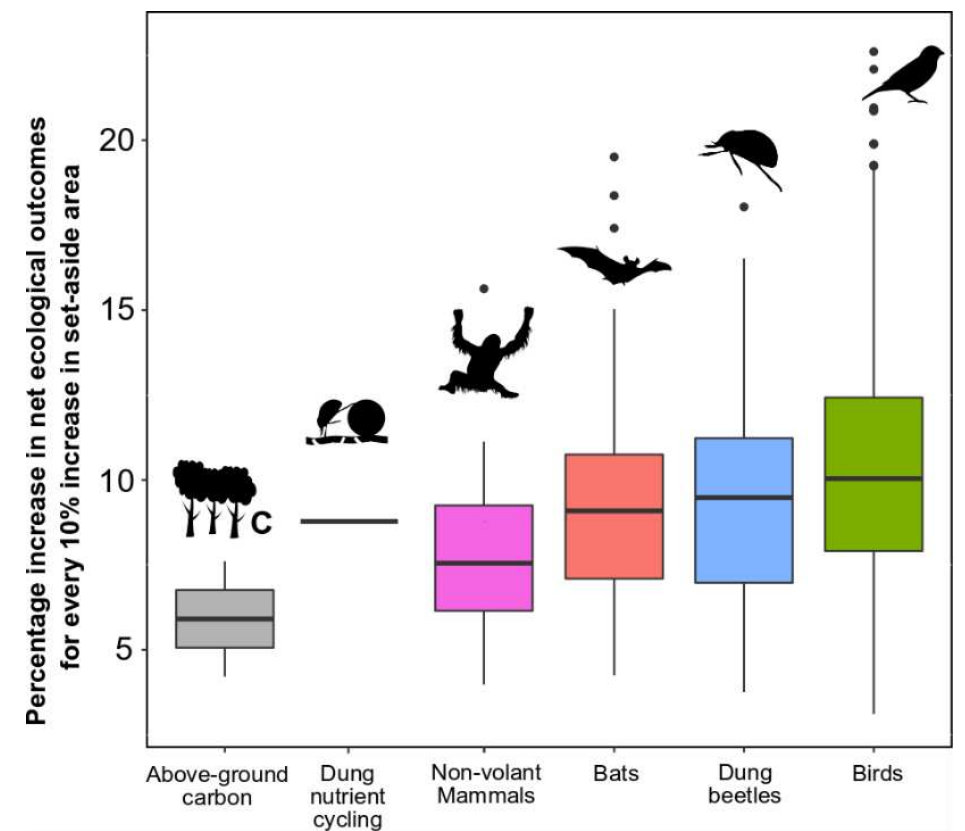

649 Fig. 3. Percentage increase in net ecological outcomes for each $\mathbf{1 0} \%$ uniform increase in

650 set-aside area

651 Boxplots of all taxonomic groups, above-ground carbon storage and dung nutrient cycling 652 showing the percentage increase in net ecological outcomes for each $10 \%$ uniform increase 653 (under landscape scenarios that range from $61-92 \%$ cultivated) in set-aside area across the 654 landscape. 


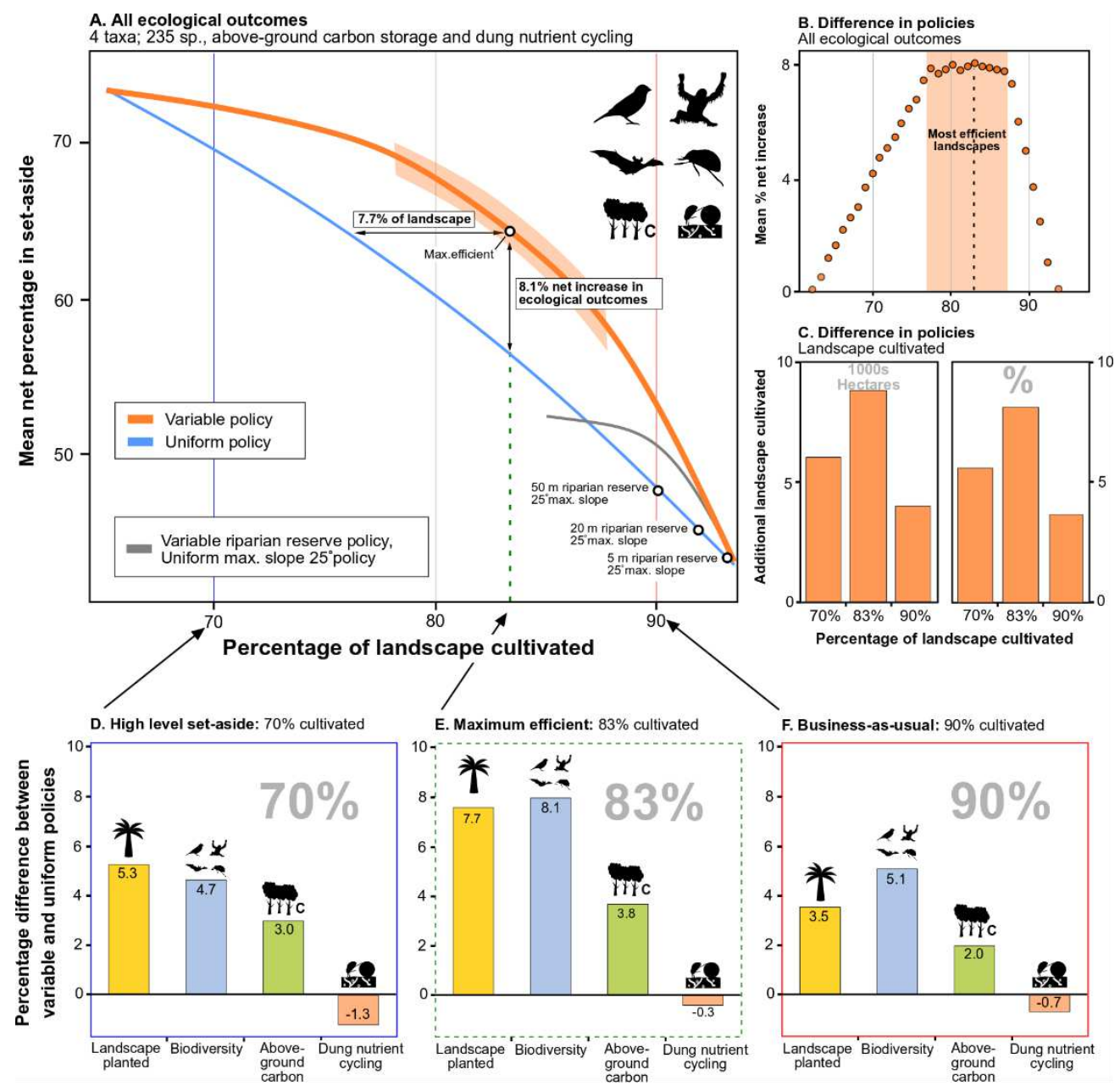

656 Fig. 4. Ecological outcomes under variable and uniform set-aside policies

657 (A) Percentage of net ecological outcomes (species occurrence, above-ground carbon storage 658 and dung nutrient cycling) against the percentage of the landscape cultivated under variable 659 (orange line) and uniform (blue line) policies. Under the uniform policy, all plantations in the 660 landscape apply the same policies for riparian reserve width and maximum slope for 661 cultivation, whereas under the variable policy these two components can vary among 662 plantations. The 'most efficient landscapes' show gains from the variable policy that are 663 obtained when set-aside configurations that result in $77-87 \%$ of the landscape cultivated (upper 664 quartile of the difference between uniform and variable policies), with the maximum difference achieved when $83 \%$ of the landscape is cultivated ('max. efficient' black and white dot). The

666 current legislation in Sabah, Malaysia $\left(25^{\circ}\right.$ maximum slope for cultivation, $20 \mathrm{~m}$ riparian 667 reserve width) and Indonesia (25 maximum slope for cultivation slope, $50 \mathrm{~m}$ riparian reserve 
width) are shown with labelled dots. Grey curve shows variable riparian policies with a uniform

669 maximum slope for cultivation of $25^{\circ}$. Curves use local polynomial regression for locally

670 estimated scatterplot smoothing (LOESS). (B) Percentage change in net ecological outcomes

671 (species occurrence, above-ground carbon storage and dung nutrient cycling) under the

672 variable policy, at all levels of the landscape cultivated. As in A, the most efficient landscapes

673 show the upper quartile of all comparisons between the policies. (C) Additional cultivation

674 area (absolute in hectares and as a percentage of the landscape) gains from adopting the variable

675 policy at 70,83 and $90 \%$ of the landscape cultivation, i.e. possible ecological gains for

676 equivalent ecological outcomes. (D-F) Net percentage gains for landscape cultivated, species

677 occurrence, above-ground carbon storage, and dung nutrient cycling from adopting the variable

678 policy at 70,83 and $90 \%$ of the landscape cultivated. 

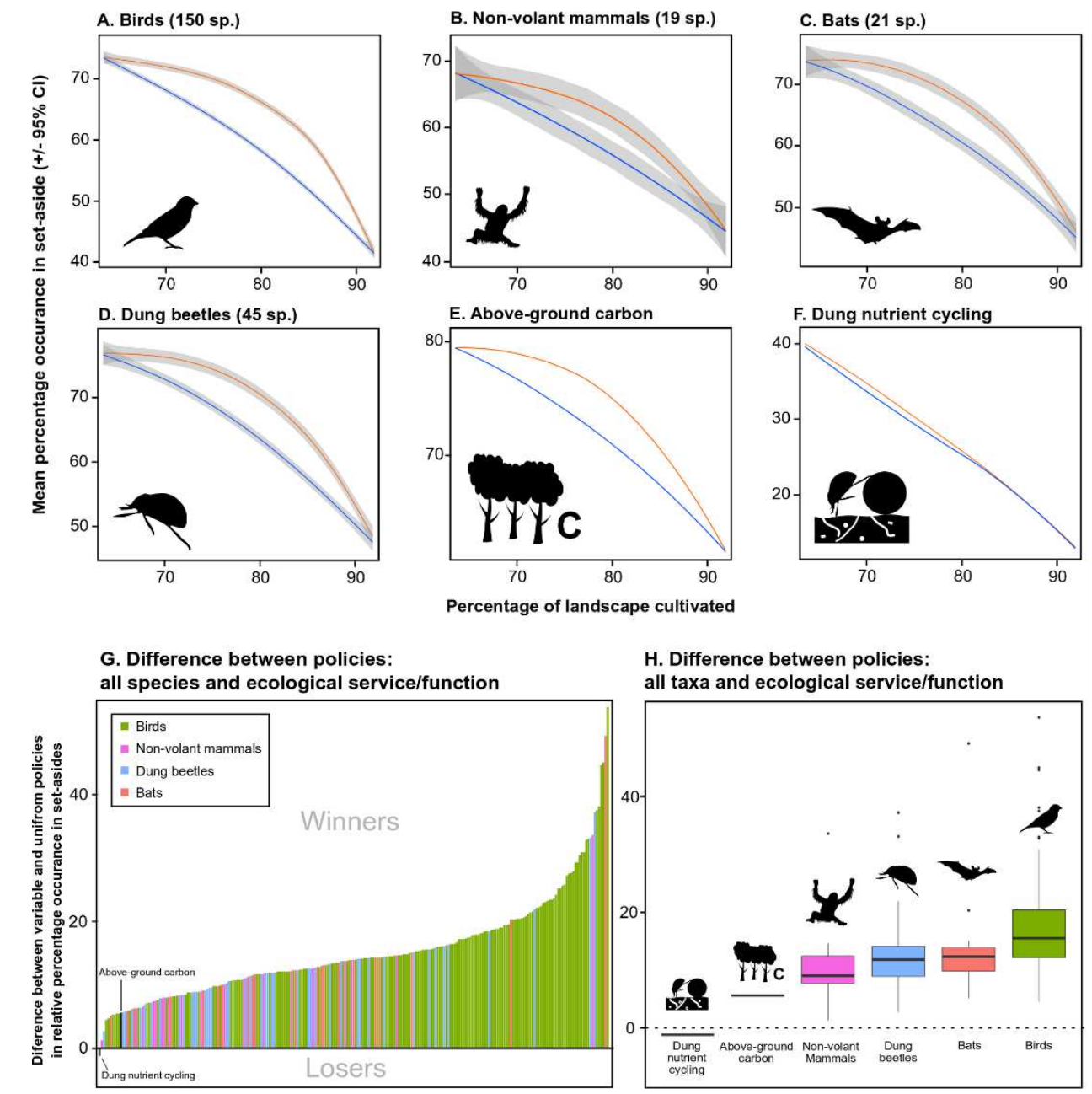

680 Fig. 5. Taxon and ecological service/function specific ecological outcomes under variable

682 (A-F) Trade-off curves of the percentage change in net ecological outcomes (species 683 occurrence, above-ground carbon storage and dung nutrient cycling) in set-aside (mean $\pm 95 \%$

684 CI) against the percentage of landscape cultivated. Under the uniform policy, all plantations in 685 the landscape apply the same policies for riparian reserve width and maximum slope for 686 cultivation. For the variable policy, these two components can vary between plantations. All 687 curves use local polynomial regression for locally estimated scatterplot smoothing (LOESS).

688 (G-H) Difference between policies at the 'maximum efficient' level (83\% of the landscape 689 cultivated) in terms of relative percentage occurrence in ecological outcomes (G), and boxplots for all ecological outcomes (H). 
691 Table 1. Potential for optimizing oil palm cultivation across Borneo

692 Impact of optimizing set-asides on potential palm oil production across Borneo for 70, 83 and

$69390 \%$ of landscape cultivated, comparing uniform and variable policies. Under the uniform

694 policy, all plantations in the landscape apply the same policies for riparian reserve width and

695 maximum slope for cultivation. For the variable policy, these two components can vary

696 between plantations.

\begin{tabular}{|c|c|c|c|}
\hline & $\begin{array}{l}\text { High level set-aside } \\
70 \% \text { of landscape } \\
\text { cultivated }\end{array}$ & $\begin{array}{c}\text { Maximum efficient } \\
83 \% \text { of landscape } \\
\text { cultivated }\end{array}$ & $\begin{array}{c}\text { Business-as-usual } \\
90 \% \text { of landscape } \\
\text { cultivated }\end{array}$ \\
\hline $\begin{array}{l}\text { Potential percentage of additional } \\
\text { land cultivated }\end{array}$ & 5.3 & 7.7 & 3.5 \\
\hline $\begin{array}{l}\text { Potential additional bio-physically } \\
\text { suitable land cultivated on Borneo }\end{array}$ & & 30 million hectares & \\
\hline $\begin{array}{l}\text { Potential average additional oil } \\
\text { palm trees }{ }^{1}\end{array}$ & 199 million & 288 million & 131 million \\
\hline $\begin{array}{l}\text { Potential average additional CPO } \\
\text { yield over } 20 \text { years (metric tons) }\end{array}$ & 130 million $\mathrm{t}$ & 189 million $\mathrm{t}$ & 86 million $\mathrm{t}$ \\
\hline \multicolumn{4}{|c|}{${ }^{1}$ Given 125 trees per planted hectare (data from plantations $\mathrm{C}$ and $\mathrm{D}$ ). } \\
\hline \multicolumn{4}{|c|}{${ }^{2}$ Given average yield values of 4.1 metric tons of crude palm oil (CPO) per hectare per year, assuming an oi } \\
\hline \multicolumn{4}{|c|}{ extraction rate of $25 \%$, and average fresh fruit bunch yield of 16.4 metric tons per hectare per year. Data fron } \\
\hline \multicolumn{4}{|c|}{ plantations $\mathrm{C}$ and $\mathrm{D}$, which are close to the average of 4.2 metric tons of $\mathrm{CPO}$ per hectare per year for Malaysi } \\
\hline
\end{tabular}


Figures

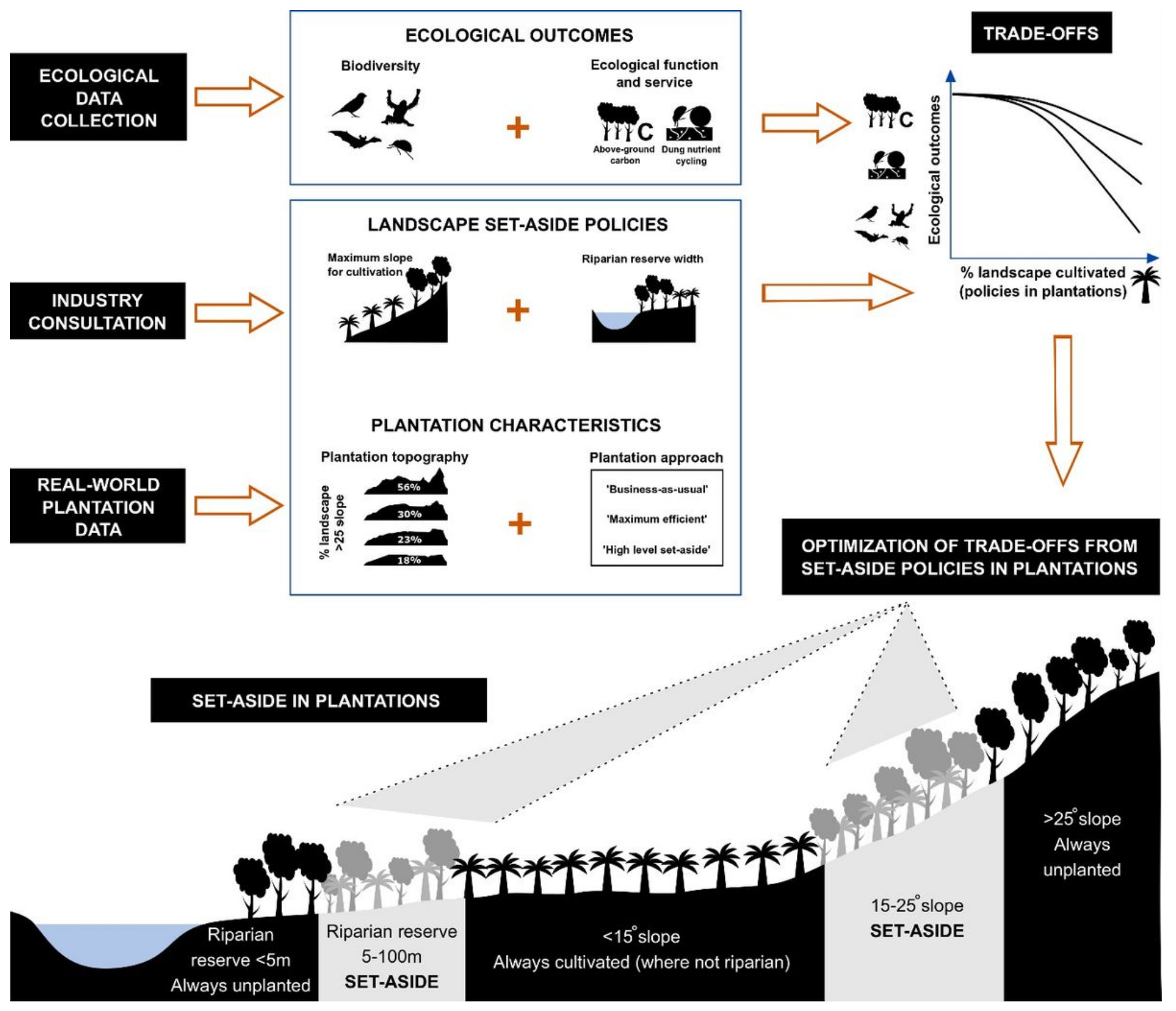

Figure 1

Study workflow 
A. Riparian reserve width vs percentage cultivated

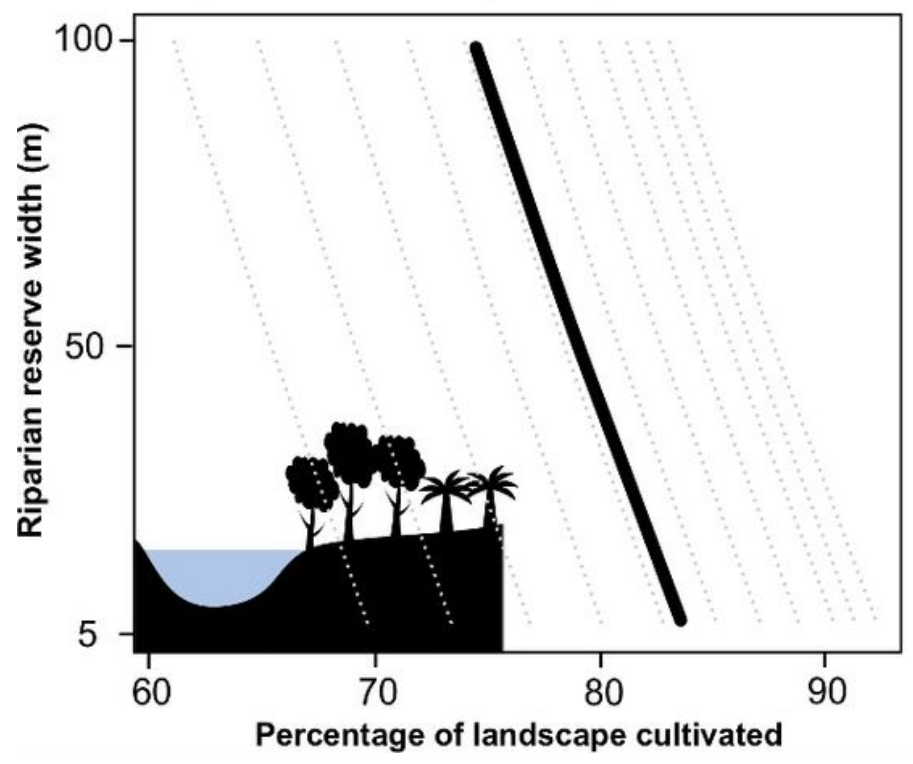

B. Maximum slope for cultivation vs percentage cultivated

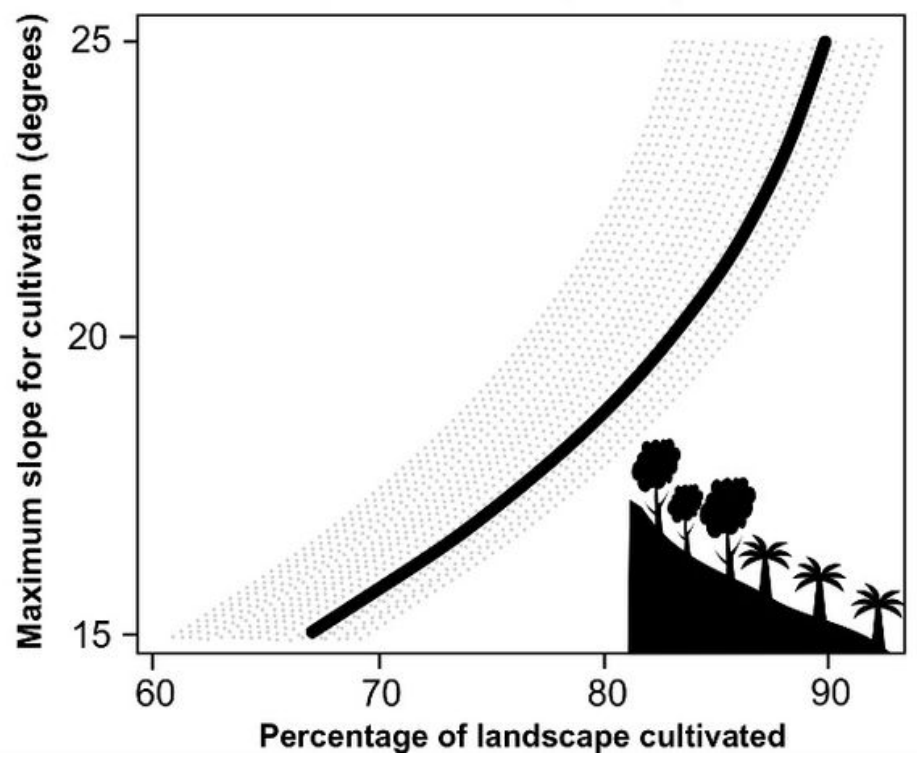

Figure 2

Impacts of set-aside configurations on percentage of landscape cultivated (A) Relationship between riparian reserve width and the percentage of the landscape cultivated. (B) Relationship between maximum slope for cultivation and percentage of the landscape cultivated. Dashed lines show all potential landscape set-aside configurations, and bold lines show the mean. 


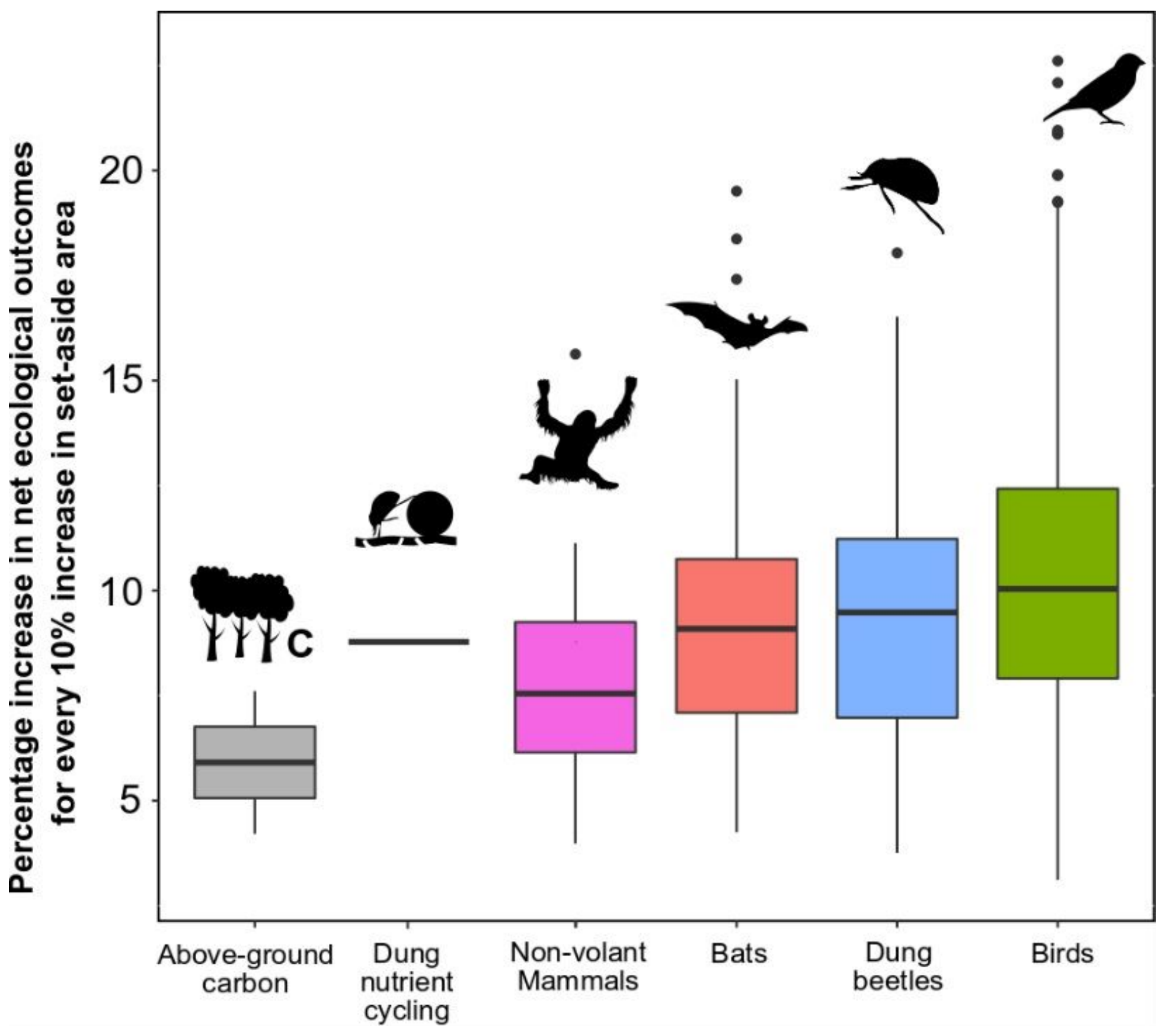

Figure 3

Percentage increase in net ecological outcomes for each $10 \%$ uniform increase in set-aside area Boxplots of all taxonomic groups, above-ground carbon storage and dung nutrient cycling showing the percentage increase in net ecological outcomes for each $10 \%$ uniform increase (under landscape scenarios that range from $61-92 \%$ cultivated) in set-aside area across the landscape. 
A. All ecological outcomes

4 taxa; 235 sp., above-ground carbon storage and dung nutrient cycling

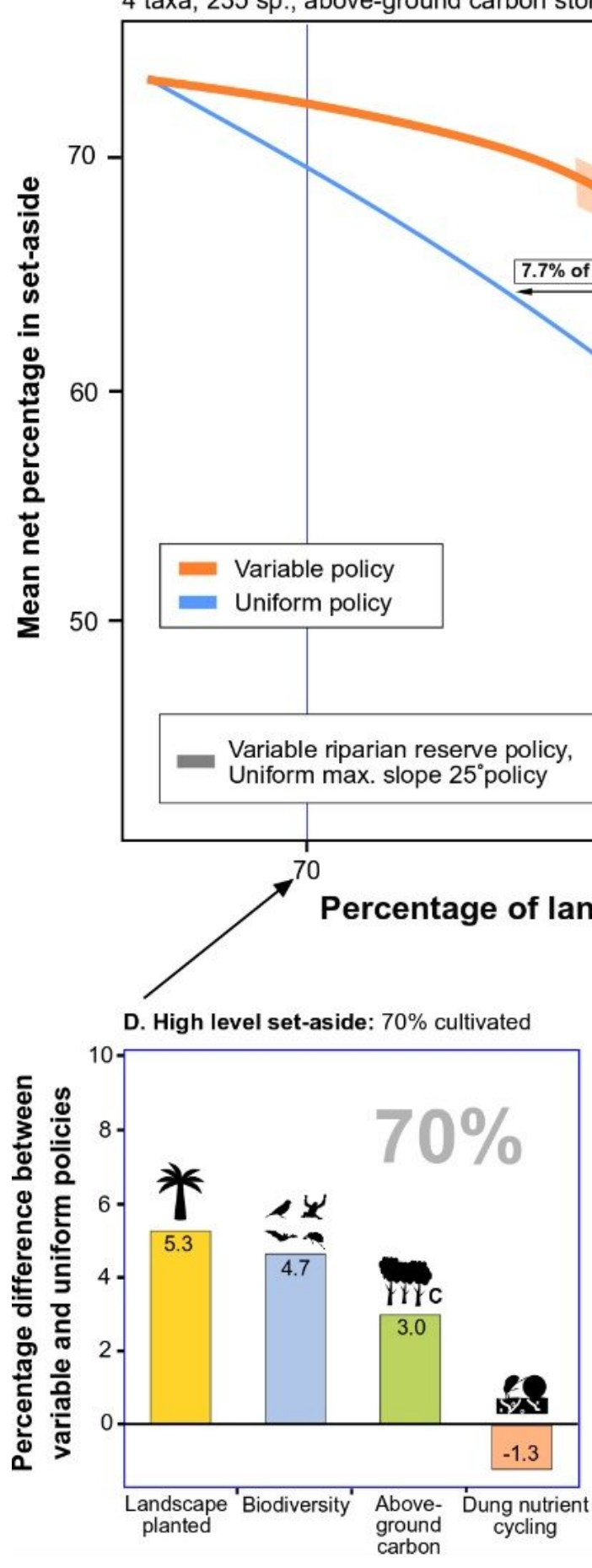

B. Difference in policies

All ecological outcomes

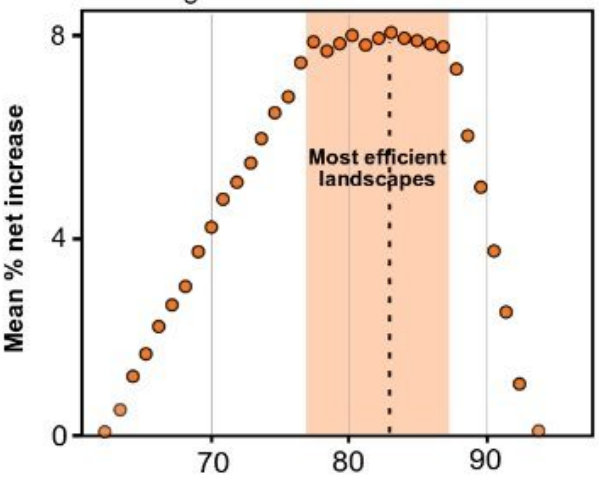

C. Difference in policies

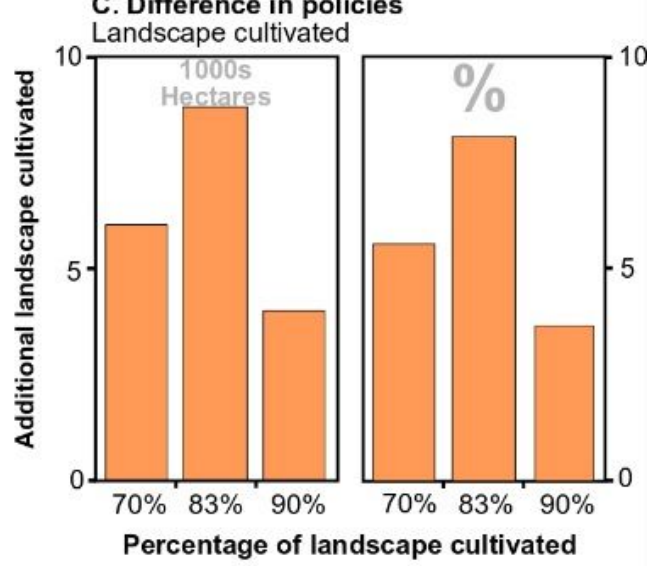

Figure 4

Ecological outcomes under variable and uniform set-aside policies (A) Percentage of net ecological outcomes (species occurrence, above-ground carbon storage and dung nutrient cycling) against the percentage of the landscape cultivated under variable (orange line) and uniform (blue line) policies. Under the uniform policy, all plantations in the landscape apply the same policies for riparian reserve width and maximum slope for cultivation, whereas under the variable policy these two components can vary among plantations. The 'most efficient landscapes' show gains from the variable policy that are obtained when set-aside configurations that result in $77-87 \%$ of the landscape cultivated (upper quartile 
of the difference between uniform and variable policies), with the maximum difference achieved when $83 \%$ of the landscape is cultivated ('max. efficient' black and white dot). The current legislation in Sabah, Malaysia ( $25^{\circ}$ maximum slope for cultivation, $20 \mathrm{~m}$ riparian reserve width) and Indonesia $\left(25^{\circ}\right.$ maximum slope for cultivation slope, $50 \mathrm{~m}$ riparian reserve width) are shown with labelled dots. Grey curve shows variable riparian policies with a uniform maximum slope for cultivation of $25^{\circ}$. Curves use local polynomial regression for locally estimated scatterplot smoothing (LOESS). (B) Percentage change in net ecological outcomes (species occurrence, above-ground carbon storage and dung nutrient cycling) under the variable policy, at all levels of the landscape cultivated. As in A, the most efficient landscapes show the upper quartile of all comparisons between the policies. (C) Additional cultivation area (absolute in hectares and as a percentage of the landscape) gains from adopting the variable policy at 70, 83 and $90 \%$ of the landscape cultivation, i.e. possible ecological gains for equivalent ecological outcomes. (D-F) Net percentage gains for landscape cultivated, species occurrence, above-ground carbon storage, and dung nutrient cycling from adopting the variable policy at 70,83 and $90 \%$ of the landscape cultivated. 


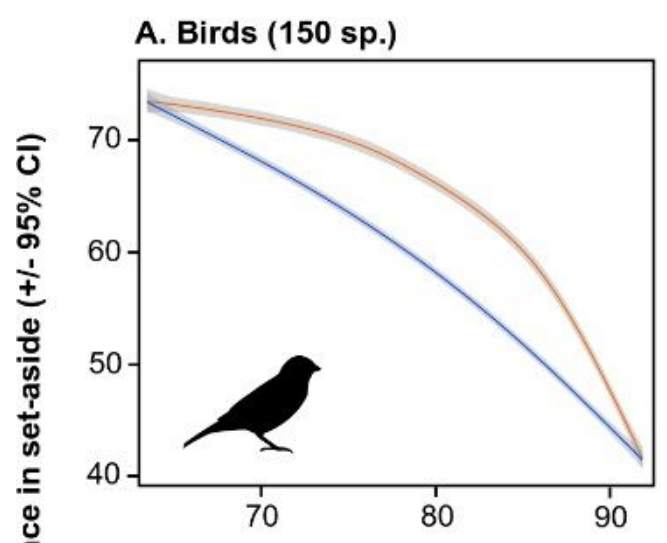

D. Dung beetles (45 sp.)

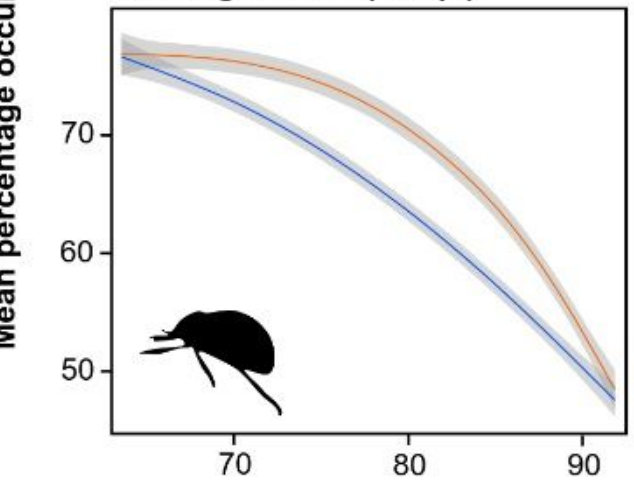

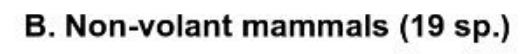

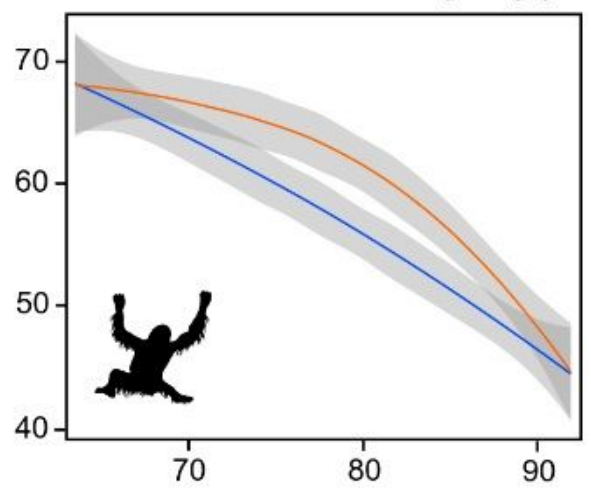

E. Above-ground carbon

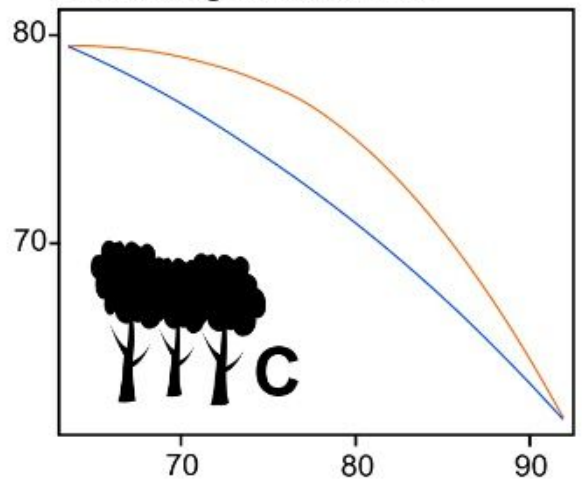

Percentage of landscape cultivated

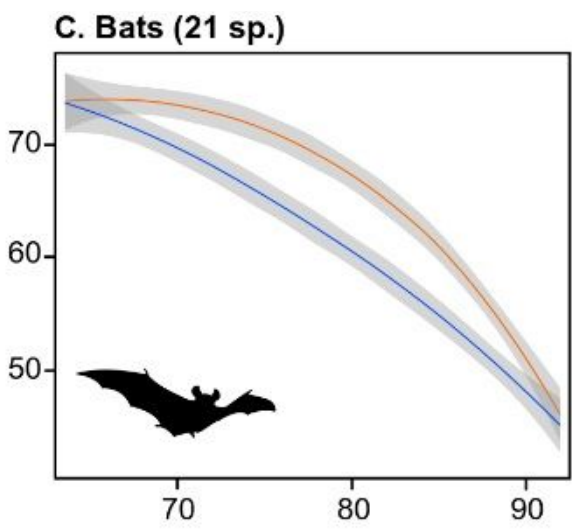

F. Dung nutrient cycling

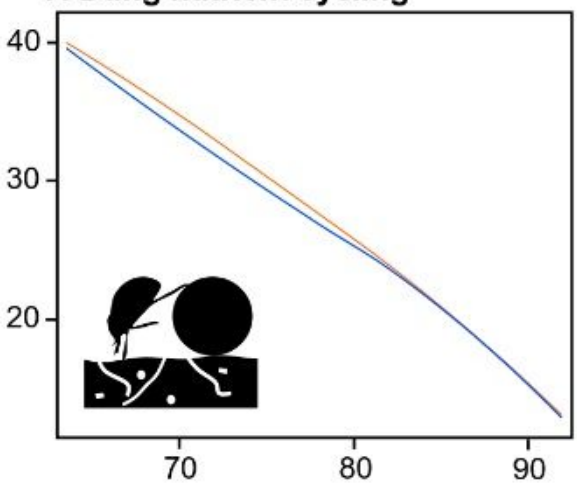

G. Difference between policies:

all species and ecological service/function

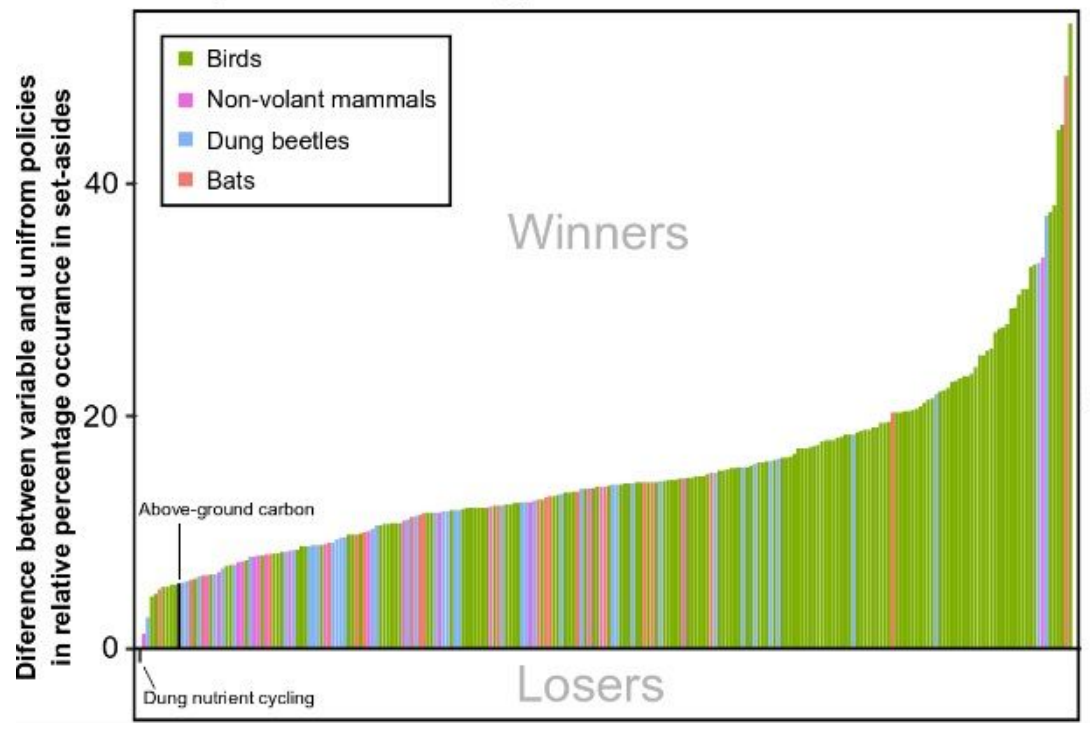

H. Difference between policies:

all taxa and ecological service/function

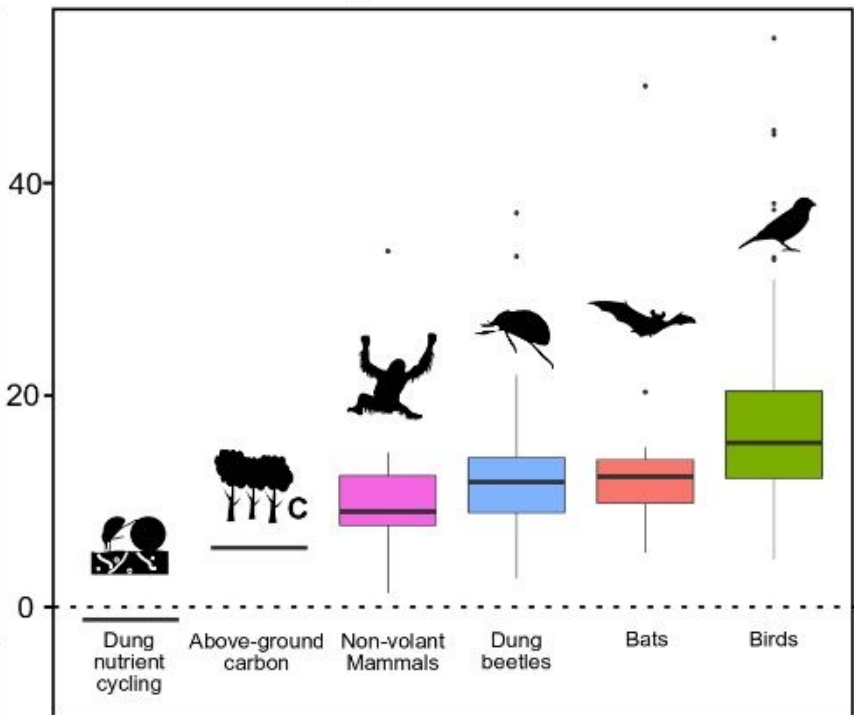

\section{Figure 5}

Taxon and ecological service/function specific ecological outcomes under variable and uniform set-aside policies (A-F) Trade-off curves of the percentage change in net ecological outcomes (species occurrence, above-ground carbon storage and dung nutrient cycling) in set-aside (mean $\pm 95 \% \mathrm{Cl}$ ) against the percentage of landscape cultivated. Under the uniform policy, all plantations in the landscape apply the same policies for riparian reserve width and maximum slope forcultivation. For the variable policy, these two components can vary between plantations. All curves use local polynomial regression for locally 
estimated scatterplot smoothing (LOESS). (G-H) Difference between policies at the 'maximum efficient' level ( $83 \%$ of the landscape cultivated) in terms of relative percentage occurrence in ecological outcomes $(G)$, and boxplots for all ecological outcomes $(H)$.

\section{Supplementary Files}

This is a list of supplementary files associated with this preprint. Click to download.

- BicknelletalSupplementarylnformation.pdf 